\title{
La Comunidad Andina (CAN) desde el ámbito político*
}

\author{
The Andean Community (CAN) in the Political Sphere
}

\author{
${ }^{2}$ Carolina Blanco Alvarado* \\ ${ }^{3}$ David Echeverry Botero ${ }^{* * *}$ \\ ${ }^{4}$ Germán Ortega Ruiz ${ }^{* * *}$
}

Fecha de Recepción: 5 de mayo del 2020

Fecha de Aprobación: 25 de mayo del 2020

Este artículo es producto del proyecto de investigación Fodein "La actividad administrativa, elemento necesario para el cumplimiento de los fines del Estado", gestionado en el marco de la Facultad de Derecho de la Universidad Santo Tomas, sede de Bogotá.

Citar como: Blanco Alvarado, C., Echeverry Botero, D. y Ortega Ruiz, G. (2020). La Comunidad Andina (CAN) desde el ámbito político. Via Inveniendi et Iudicandi, 15(2), 231-248. Dor: https://doi. org/10.15332/19090528/6249

* $\quad$ Abogado por la Universidad Externado de Colombia; Ph. D. en Derecho por la Universidad Santo Tomás, sede de Bogotá; magíster en Derechos Fundamentales por la Universidad Carlos III (Madrid, España); especialista en Derecho Constitucional por el Centro de Estudios Políticos y Constitucionales (Madrid, Espańa); especialista en Derecho Administrativo por la Universidad del Rosario (Bogotá); docente e investigadora de la Universidad Santo Tomas, sede de Bogotá. E-mail: ruthblanco@usantotomas.edu.co. orcid: https://orcid. org/0000-0002-1354-4272

... Abogado y magíster en Derecho Económico por la Pontificia Universidad Javeriana; Master of Commercial Law (LLM) por la Universidad de Melbourne; docente de la Maestría en Derecho Económico de la Universidad Javeriana en las materias de Investigación Científica y Seminario de Investigación; director de proyectos de investigación en la Maestría en Derecho Contractual Público y Privado de la Universidad Santo Tomás. Se desempeña igualmente como docente de las materias de Derecho Comercial General, Sujetos de Derecho Privado y Economía Política en la Facultad de Derecho de la misma universidad. E-mail: davidecheverry@ usantotomas.edu.co. oRCID: https://orcid.org/0000-0003-1893-9836

.... Abogado por la Universidad Santo Tomás; estudiante del programa de cursos para el doctorado de la Universidad de Buenos Aires; magíster en Derecho Público de la Universidad de Constanza y de la Universidad Santo Tomás; especialista en Alta Dirección del Estado por la Escuela de Alto Gobierno; especialista en Derecho Constitucional por la Universidad del Rosario; especialista en Derecho Administrativo por la Universidad Santo Tomás. Docente de la Universidad Santo Tomas. E-mail: luis.ortega@usantotomas.edu.co. orciD: http://orcid.org/0000-0003-2957-5839 


\title{
RESUMEN
}

Este artículo pretende identificar el papel contemporáneo de la Comunidad Andina (CAN) desde el escenario de las competencias de dicha organización que irradien el escenario político. Dicha reflexión permitió concluir obstáculos en la gestión de dicho sistema de organización internacional. Por lo anterior a través del presente manuscrito se determinaron algunas propuestas de solución frente a la crisis política de la citada Organización Supranacional. La metodología de investigación es cualitativa, como quiera que el documento busca describir la perspectiva política de la caN bajo el método de investigación descriptivo y analítico.

Palabras clave: Comunidad Andina, CAN, escenario político, integración andina.

\begin{abstract}
This article aims to identify the current role of the Andean Community (CAN) with regard to the duties of that organization that affect the political scene. The article's conclusion expounds on the obstacles in the management of that system of international organization. Therefore this article defines some proposals for solutions to the political crisis of the aforementioned supranational organization. The research methodology of the article is qualitative, as it seeks to describe the political perspective of CAN under the descriptive and analytical research method.
\end{abstract}

Keywords: Andean Community, CAN, political scenario, Andean integration. 


\section{INTRODUCCIÓN}

Hace aproximadamente cuarenta años, los gobiernos de Bolivia, Colombia, Chile, Ecuador y Perú, después de concluir las acciones y procedimientos establecidos para llevar adelante las iniciativas e instrucciones presidenciales y la preparación del documento constitutivo de su agrupación, acordaron aprobar y suscribir el denominado Acuerdo de Integración Subregional. Este documento internacional, de naturaleza comunitaria, ha sido considerado como el cimiento de la construcción integracionista de los países andinos, la cual, pese a los diversos problemas ocurridos durante varias décadas, sigue siendo un proyecto común con renovada planificación y desarrollo que puede seguir adelante si se adopta una visión finalmente integradora (Gallego, 2014).

La operatividad de la integración andina se desarrolla en el marco del Estado democrático. De hecho, existe una relación de proporcionalidad entre las nociones de democracia e integración ${ }^{1}$, que se identifica en la medida en que la primera puede proporcionar mecanismos para que aquellas instituciones que se ven comprometidas por las decisiones que se toman en el ámbito de la segunda, puedan también involucrarse en ella y puedan legitimarla (Gallego, 2014).

El proceso andino de integración funciona en el marco de la garantía de la tridivisión del poder, en razón de que una de las exigencias de tipo político que se impone a los Estados que pretenden ingresar a la CaN es la de que estos se constituyan en Estados de derecho

1 En aras de fortalecer la democracia en los países miembros, estos suscribieron en 1998 el protocolo Compromiso de la Comunidad Andina por la Democracia, que pretende adoptar medidas destinadas a la protección de la democracia como supuesto esencial para intensificar los procesos de integración económica. Dicho documento permite maximizar la esfera del principio democrático en la actividad internacional de los citados Estados. Establece, además, la plena vigencia de las instituciones democráticas y el Estado de derecho como condiciones esenciales para la cooperación política y la integración económica, social y cultural en la CAN. Las disposiciones contenidas en él se aplicarán en caso de producirse una ruptura del orden democrático en cualquiera de los países miembros, en cuyo caso los demás adoptarán las medidas pertinentes para propiciar su pronto restablecimiento, sin perjuicio de lo cual podrán desarrollar gestiones diplomáticas tendientes a facilitar el restablecimiento del orden democrático en el país afectado. En este orden de ideas, ese protocolo prevé en el artículo primero que la vigencia de las instituciones democráticas y del Estado de derecho son condiciones necesarias para la cooperación política y el proceso de integración en sus niveles económico, social y cultural. Más adelante, el protocolo establece las medidas a tomar en caso de que se produjera una ruptura en el orden institucional de alguno de los países y las sanciones a las que este debiera atenerse. 
en el que los poderes legislativo, ejecutivo y judicial tengan un ámbito perfectamente delimitado. Dicha tridivisión del poder también resulta aplicable en la CAN (a través del Consejo Andino de Ministros de Relaciones Exteriores, Parlamento Andino y Tribunal Andino de Justicia), solo que el análisis de la tridivisión del poder en el marco de la CAN es más complejo que en el Estado colombiano. Ello obedece a la necesidad de mantener el equilibrio entre los intereses de la CAN, representados principalmente por la Comisión y la Secretaria General de la CAN, y los de los Estados miembros, representados fundamentalmente por el Consejo Andino de Presidentes y el Consejo de Ministros de Relaciones Exteriores (Maside Miranda, 1992).

\section{Principales dificultades de ORden POLÍtico}

\section{PARA EL FUNCIONAMIENTO DE LA CAN}

El proceso andino de integración ha respondido a una política de gobierno y, como consecuencia de ello, su desarrollo depende de la discrecionalidad del nivel del poder central, esto es, de los gobiernos nacionales de los países miembros. En este orden de ideas, el contenido, alcance y condiciones de aplicación de las políticas comunitarias pueden suscitar algunas divergencias que, sin duda, irán aumentando hacia futuro. Obviamente, la solución no puede consistir en ocultar los problemas o en imponer soluciones unilaterales generadoras de nuevos conflictos. Se trata, por el contrario, de crear un marco de relaciones susceptible de favorecer el consenso pre- y posdecisional entre los actores implicados (Morata, 1987). En esta perspectiva, la colaboración interna de los órganos e instituciones que conforman el Sistema Andino de Integración (SAI) con los órganos internos de los Estados miembros es de relevancia (Blanco, 2013b).

\section{CONDICIONES DE ORDEN POLÍTICO PARA LA OPERANCIA DE LA CAN}

Como elementos de orden político que se configuran como absolutamente necesarios para lograr el objetivo de funcionamiento de la CAN, se encuentran los siguientes: 
En primer lugar, es indispensable la voluntad política de cesión del ejercicio de soberanía por parte del Estado colombiano a la CAN, ya que, en cuanto a organización institucional del proceso andino de integración, es indispensable la cesión del ejercicio de la soberanía por parte de los Estados miembros a las instituciones comunitarias. Esto implica evitar una estructura institucional que se fundamente en la cooperación intergubernamental o un sistema intergubernamental y no supranacional.

En segundo lugar, es indispensable consolidar la legitimidad del proceso andino de integración. Para que el proceso andino de integración produzca efectos es indispensable la participación activa de la ciudadanía en el poder político propio de la CAN² ${ }^{2}$ La integración no es suficiente en sí misma para declarar su legitimidad, "son los actores políticos y sociales quienes, a través de la participación en estos procesos, otorgan la legitimidad, pues es la creencia popular lo más importante para alcanzar este objetivo" (Barros, 1989, pp. 17-18). La legitimidad del proceso andino de integración, para que produzca los efectos deseados, requiere:

- Participación de la ciudadanía andina en los consejos consultivos de la CAN: las políticas de participación ciudadana en la CAN se enmarcan en el eje de participación de la sociedad civil, incluido como línea de acción de la Agenda Social Andina ${ }^{3}$,

2 Existen dos principios que se consideran básicos para el funcionamiento correcto de la caN: el principio de igualdad democrática y el principio de democracia representativa y participativa. El principio de igualdad democrática supone el respeto, por parte de la CAN, de sus ciudadanos, en lo que se refiere al normal desarrollo de todas sus actividades, con lo cual quedan encargadas las instituciones de la CAN de atender de manera igualitaria las distintas pretensiones ejercidas por todos los ciudadanos. El principio de democracia representativa y participativa es un mandato de optimización que encaja en el ámbito del diálogo abierto, transparente y regular que las distintas instituciones de la CAN han de mantener con los ciudadanos, las asociaciones representativas y la sociedad civil. Dicho diálogo tiene lugar a través de los cauces adecuados y puede afectar todos y cada uno de los campos de acción de la Can. Dicho principio se encuentra en distintas manifestaciones. En primer lugar, en el Parlamento Andino, que representa a los ciudadanos de la CAN mientras que los Estados miembros lo están mediante el Consejo Andino de Presidentes y el Consejo de Ministros por sus gobiernos. En tercer lugar, los ciudadanos tienen derecho a participar en la vida democrática de la can (Molina del Pozo, 2005).

3 La Comunidad Andina ha intentado impulsar y canalizar la inclusión de la sociedad civil en el proceso de integración subregional andino a través del desarrollo de tres ejes fundamentales: el primer eje se ha proyectado mediante la labor de los consejos consultivo empresarial y laboral andinos. El segundo eje está compuesto por la participación de actores no gubernamentales en la definición de algunos programas, como son la Estrategia Regional de la Biodiversidad, el Plan Integrado de Desarrollo Social y la Estrategia Andina para la Prevención 
manifestada, además, a través de la formulación y presentación de las opiniones o puntos de vista de los consejos consultivos empresarial y laboral andinos y mediante el dialogo y la concertación de los intereses de los pueblos indígenas ${ }^{4}$. Se aboga también y por la participación de los consumidores y los municipios. Esto obedece a que el Acuerdo de Cartagena, en el literal C del artículo 129, prevé que "los países miembros emprenderán acciones de cooperación conjunta destinados a contribuir al logro de los siguientes objetivos de desarrollo social de la población andina: [...] Participación plena del habitante de la subregión en el proceso de integración”.

- Elecciones directas de parlamentarios andinos: en los verdaderos procesos de integración se evidencia la existencia de instancias que tienen por principio constitutivo la representación ciudadana, a través de los parlamentos, donde se concentra el principio de delegación (representación) de la voluntad popular y que pretenden elaborar políticas comunes a todos los países que ceden el ejercicio de competencias soberanas frente a un esquema de integración. Esto permite al ciudadano participar democráticamente en el ejercicio del poder comunitario. En el proceso andino de integración existe el Parlamento Andino, conformado por parlamentarios designados por elección popular por Ecuador y Perú, sin que Bolivia y Colombia

y Atención de Desastres, entre otras. El último gran campo de trabajo son las instancias consultivas, como la Mesa de Trabajo sobre Derechos de los Pueblos Indígenas, que no se ha puesto en vigor debido a que aún no se han asignado y acreditado los representantes de cada nación; la Mesa Andina de Participación de la Sociedad Civil para la Defensa de los Derechos del Consumidor, instancia que aún no está en funcionamiento, y el Consejo Consultivo Andino de Autoridades Municipales, que se ha reunido en muy pocas ocasiones

4 Para el efecto, la CAN, mediante Decisión núm. 674 creo el Consejo Consultivo de los Pueblos Indígenas de la Comunidad Andina. Dicha Decisión estableció el Consejo Consultivo de los Pueblos Indígenas de la Comunidad Andina como instancia consultiva en el marco del Sistema Andino de Integración, con el fin de promover la participación activa de los pueblos indígenas en los asuntos vinculados con la integración subregional, en sus ámbitos económico, social, cultural y político. De conformidad con el artículo 3. ${ }^{\circ}$ de la citada Decisión, se asignaron como funciones del citado Consejo: 1) emitir opinión ante el Consejo Andino de Ministros de Relaciones Exteriores y la Comisión o la Secretaría General de la Comunidad Andina, según corresponda, por propia iniciativa o a requerimiento de estos, sobre asuntos vinculados con la participación de los pueblos indígenas en el proceso de integración subregional; 2) asistir a las reuniones de expertos gubernamentales o grupos de trabajo vinculados a sus actividades, a las que fuere convocado por decisión de los países miembros; 3) participar con derecho a voz en las reuniones del Consejo Andino de Ministros de Relaciones Exteriores y de la Comisión de la Comunidad Andina; 4) promover el intercambio, evaluación y difusión de experiencias y prácticas exitosas, el fortalecimiento organizativo y, en general, la cooperación entre pueblos u organizaciones indígenas, entidades del Estado y organismos de derechos humanos y organizaciones de la sociedad civil de los países miembros; y 5) elaborar y aprobar su reglamento en el marco de lo dispuesto en la presente decisión. 
presenten a la fecha elección popular de parlamentarios y, como consecuencia de ello, sean cinco congresistas bolivianos y colombianos los que desempeñen las funciones de parlamentarios andinos por este país (Blanco, 2013a).

- Cultura politica de integración: entendemos por cultura política el conjunto de valores, creencias, costumbres, tradiciones y orientaciones que poseen los individuos hacia el sistema político o los objetos políticos, lo que conlleva a pensar en la existencia de una concepción sobre la vivencia en torno del quehacer político. Este concepto permite explicar las conductas, valores, actitudes y creencias respecto del sistema político y del ciudadano inmerso en una sociedad democrática (Ortiz Jiménez, 2007). La cultura política de integración supone el conocimiento y la práctica de la razón de ser del proceso andino de integración por parte de la ciudadanía andina; esto es, la gestión práctica de dicho proceso en las acciones y omisiones de la población andina (Blanco, 2013c).

En concordancia con lo dispuesto anteriormente, es importante la concientización de la necesidad de la integración andina. Esta implica un proceso largo que por necesidad habrá de comprometer las voluntades de algunas generaciones. "Por ello es fundamental que los jóvenes que hoy cursan sus estudios escolares conozcan y valoren el reto que significa construir una comunidad de naciones y la urgencia de hacerlo para enfrentar los enormes desafíos de la globalización" (Blanco, 2015b, p. 56); todo ello, con la finalidad de que la gente sienta común el proceso andino y se sienta parte de él. Para el efecto, es necesario remitirse a lo dispuesto por el profesor Ayala, rector de la Universidad Andina Simón Bolívar: "Los procesos de integración demandan una base social que los sustente. La educación es un elemento clave en el desarrollo de esa base social” (Ayala, 2007, p. 15). Es por lo anterior por lo que una de las principales preocupaciones de los órganos comunitarios andinos debería ser la del fomento de la enseñanza de integración en los países andinos 5 .

5 La educación para la participación se impone como respuesta ante la necesidad de generar una nueva cultura de la participación que permita ayudar a la formación de personas que puedan ser protagonistas activos del poder político y que, de esta manera, puedan ser capaces de ejercer y defender plenamente sus derechos ciudadanos (Jablkowski, 2008). Para ello, es necesario trabajar en favor de que los ciudadanos internalicen el valor de las instituciones democráticas, en aras de evitar que obren solamente como espectadores pasivos. Para efectos del proceso de integración andina y atendiendo lo dispuesto anteriormente, es necesario contribuir a la producción 
Un proceso de integración sin un fuerte y sistemático esfuerzo educativo que lo acompañe y lo refuerce no es sostenible. Por ello, los compromisos de los países en el campo de la integración económica y política solo se cristalizaran en el largo plazo, cuando estos estén acompañados de un esfuerzo por desarrollar una cultura integracionista ${ }^{6}$.

Es importante anotar que, en el escenario mundial, el surgimiento de una sociedad moderna se caracteriza por la omnipresencia de los bienes disponibles y el aumento del conocimiento y la comunicación. En este contexto, la planificación educativa neoliberal de los Estados posmodernos debe redefinir sus actividades; por ejemplo, la innovación en los métodos de enseñanza, la creación de programas y proyectos para lograr una educación más flexible y pertinente, el mejoramiento de la condición humana y la calidad de vida de la nación y el mejoramiento de las relaciones entre la sociedad y el Estado (Ruano, 2006). Lo anterior supone cambiar los hábitos y la cultura de la comunidad escolar y promover una participación más activa de todos los sujetos en el diseño, implementación y evaluación de las políticas nacional, local e institucional de la educación (Ramírez, 2006). Se requiere, además, mejorar las posibles alianzas con otras partes interesadas en intervenir en la prestación del servicio educativo, como son los empresarios, las asociaciones de industriales y las organizaciones internacionales, entre otros (Quiroz, 2014).

- Consolidación de la ciudadanía andina: es necesaria identificar a los habitantes del territorio andino como ciudadanos y ciudadanas andinos, a través de la libre circulación de personas en cualquier condición en el territorio andino. En la filosofía jurídico-política contemporánea se habla de "ciudadanía" en varios sentidos diferentes, pero en estas paginas, dicho concepto se entiende como la pertenencia a una comunidad política que se autogobierna, es decir, de formar parte de un cuerpo político cuyos miembros tienen derecho a participar como

de un cambio de mentalidad, a la construcción de una mentalidad democrática que comprenda y valorice el proceso de integración andino, lo que supone la enseñanza de la integración andina.

6 De conformidad con Blanco, un proceso de integración sin un fuerte y sistemático esfuerzo educativo que lo acompañe y refuerce no es sostenible. Los compromisos de los países en el campo de la integración económica y política solo se cristalizan en el largo plazo cuando convergen junto con un esfuerzo por desarrollar una cultura integracionista en el seno de las sociedades (Blanco, 2015a). 
iguales, directamente o a través de representantes, en la toma de las decisiones públicas (Bayón Mohino, 2007). En concordancia con el citado concepto, la ciudadanía se puede entender como el conjunto de prácticas (jurídicas, políticas, económicas y culturales) que definen a una persona como miembro competente de una sociedad (Liwski, 2006).

\begin{abstract}
Abordar un concepto sobre la noción de ciudadanía andina ${ }^{7}$ implica, en primera instancia, tener presente que "la dimensión territorial o espacial de la ciudadanía, es decir, aquella vinculada a la relación entre el Estado nación y la sociedad civil, se halla actualmente en plena reformulación, ya que algunos autores han comenzado a ensayar concepciones de ciudadanía multilateral o amplia, ligadas no solo al vinculo único y exclusivo entre individuo y Estado nación” (Pérez Luño, 2002, pp. 177-211). Es en este sentido como el proceso de integración andino requiere el reconocimiento de una ciudadanía andina activa, basada en la participación política y cívica, y que vele por el conjunto de libertades, derechos y garantías que se sumen y confieran un valor añadido a las ciudadanías nacionales ${ }^{8}$ (Blanco, 2014).
\end{abstract}

La ciudadanía andina asegura sentido de pertenencia a la comunidad y afianzamiento de una identidad andina, basada en el reconocimiento de valores democráticos e

7 Algunas de las características que podrían tipificar la noción de la ciudadanía andina son: 1) la ciudadanía andina la adquiere toda persona que ostente la nacionalidad de un Estado miembro; 2) la ciudadanía andina es complementaria y no sustitutiva de la ciudadanía nacional, ya que no la elimina. La ciudadanía andina coexiste y presupone la ciudadanía de un Estado miembro; es decir, la nacionalidad de un Estado miembro es condición sine qua non para ser ciudadano de la Comunidad Andina; 3) la ciudadanía andina significa que las personas no pueden ser objeto de discriminaciones en el ejercicio de sus derechos ni por parte de las autoridades públicas (administrativa o judicial) ni por otros particulares en cualquier Estado miembro; 4) la ciudadanía andina supone el derecho de todo ciudadano de la Comunidad Andina a residir en un Estado miembro del que no sea nacional y a elegir y ser elegido en las elecciones al Parlamento Andino en el Estado miembro en el que resida, en las mismas condiciones que los nacionales de dicho Estado; 5) la ciudadanía andina supone el derecho a todo ciudadano de la Comunidad Andina a circular y residir libremente en el territorio de los Estados miembros, con sujeción a las disposiciones adoptadas para su aplicación.

8 En principio, podría afirmarse que la importancia de la noción de ciudadanía andina radica en el reconocimiento de derechos humanos, por parte de todos y cada uno de los países miembros, a los nacionales de países andinos diferentes al propio. Lo anterior obedece a que el concepto de ciudadanía, en un proceso de integración, mantiene una relación de tensión con la exigencia de universalidad de los derechos humanos; sin embargo, hay que tener en cuenta que, a pesar de esa contradicción, los conceptos de derechos humanos y de derechos ciudadanos no solo tienen un origen común, sino que se precisan mutuamente, son complementarios y difícilmente pueden subsistir el uno sin el otro (De Donini, 2014) 
interculturales, en el respeto de los derechos humanos, en la no discriminación por razón de la nacionalidad y en un conjunto de libertades y derechos sociales, ambientales, culturales y económicos que los nacionales de los países miembros de la Comunidad pueden ejercer en un territorio integrado (Humbarita, 2015). Ahora bien, es pertinente anotar que el éxito de la ciudadanía andina está íntimamente ligado a la labor de reforzar y potenciar la identidad andina, haciendo que los ciudadanos se sientan partícipes y actores del proceso de integración comunitaria; de esta manera se crea así una ciudadanía supranacional, que congrega las diversas ciudadanías estatales en un proyecto político común (Barragán, 2016).

Otra condición para que opere el proceso andino de integración es la coordinación de la institucionalidad que conforma a la CAN. La pertenencia al Sistema Andino de Integración (SAI) supone, por parte de los países miembros, la obligación de actuar de acuerdo con el objetivo único de la consecución de los objetivos del Acuerdo de Cartagena (Palomares y Calonje, 2015). Ello quiere decir que el SAI debe conformar una unidad de acción coherente que respete y dé cumplimiento al acuerdo de Cartagena y, por extensión, al derecho andino. En consecuencia, los órganos e instituciones que integran el SAI deben ajustar su funcionamiento a pautas de conducta que tiendan de forma unitaria a la consecución de los objetivos comunitarios. Lo anterior no es mas que el "principio de unidad, el cual impone y permite garantizar un funcionamiento institucional coherente y centrífugo, en el que la actuación de los distintos órganos se oriente en una misma dirección, evitando la dispersión institucional" (Quindimil, 2006, p. 145,146).

Ahora bien, la referenciada unidad supone a la vez autonomía en el ejercicio de las funciones de los órganos comunitarios. Para el efecto, se entiende por autonomía "la necesidad de que cada órgano pueda disponer y hacer uso de los procedimientos y criterios de actuación que considere oportunos y convenientes, así como de los medios humanos, materiales y jurídicos necesarios para el adecuado cumplimiento de su función, sin que su funcionamiento pueda verse condicionado, perturbado o influido por factores ajenos a su propia voluntad" (Quindimil, 2006, p. 148). En concordancia con lo dispuesto antes, es necesario no olvidar que "la supranacionalidad en la Comunidad Andina (CAN) supone autonomía e independencia de los órganos comunitarios que conforman al Sistema Andino de Integración, lo que implica que los mismos no deban obedecer instrucciones, ni responder ante los gobiernos de los Estados miembros" (Magilevich, 1972, p. 19). 
Presupuesto de orden político indispensable para que el proceso andino de integración funcione es la voluntad política de los Estados que conforman la CAN, en el sentido de promover y fortalecer el proceso andino de integración ${ }^{9}$. Lo anterior, en razón de que el modelo de integración andino requiere de la voluntad política de sus Estados fundadores con el fin de transferir plenamente el ejercicio de competencias soberanas a la comunidad, en el propósito de conseguir objetivos e ideales compartidos (Forero Salcedo, 2014). Dicha tarea implica la puesta en común de parcelas soberanas o, dicho de otro modo, ejercicio conjunto de soberanía (Molina del Pozo, 2005).

En el marco del proceso andino de integración, se evidencia la existencia en los países andinos de regímenes presidenciales con fuertes poderes del ejecutivo, lo que ha propiciado que esos poderes cumplan un rol determinante en el proceso de integración andina. Ello da lugar a que los ejecutivos de los Estados andinos absorban todas las atribuciones de gestión del proceso de integración andino, y las ejerzan en virtud de su competencia de manejar las relaciones internacionales (Garzón, 2013).

Ahora bien, es necesaria la configuración de la integración andina como política de Estado. Resulta indispensable que la integración andina deje de ser una política de gobierno y se transforme en una política de Estado. Esto es, en una política de interés y de impacto en toda la población colombiana ${ }^{10}$ (Guarín y Aldana, 2016). Para el efecto, es pertinente anotar que el proceso de integración aún sigue siendo vulnerable por los cambios de gobierno de las naciones andinas, consecuencia de que su orientación, en la mayoría de los casos, ha dependido de políticas de gobierno y no de Estado. Esto ha permitido que la concepción sobre integración y el cumplimiento de los compromisos adquiridos en el marco de esta se vean condicionados por la ideología política del gobernante de turno en cada país andino (Tirado, Bedoya y Blanco, 2016).

9 Dicha voluntad política conlleva el fortalecimiento del principio de progresividad en las competencias de la CAN; es en este sentido como resulta procedente anotar que, para que el proceso andino de integración produzca efectos en el marco de la descentralización territorial, es necesario fortalecer el principio de progresividad; es decir, la formación gradual de la integración en las diferentes áreas de conocimiento de la CAN (Patarroyo y Benavides, 2014).

$10 \mathrm{Al}$ respecto, resulta pertinente referirse al profesor Ayala, para quien "los gobiernos y la Secretaría General de la CAN deben priorizar la enseñanza de la integración como una política de estado, que vaya más allá de los planes gubernamentales de corte coyuntural, para convertirse en una actividad permanente de todos nuestros sistemas educativos" (Ayala, 2007, p. 99). 
Otro presupuesto de orden político que permite que el proceso andino de integración funcione es la articulación entre el plan de desarrollo del Estado colombiano y las políticas del proceso andino de integración. Hoy no puede entenderse como cometido estatal fundamental nada distinto del desarrollo integral de un Estado, para cuya satisfacción plena debe imponerse, de manera gradual y racional, una verdadera política de planificación (Herrera, 2001). En este sentido, el proceso andino de integración permite armonizar políticas sociales y económicas de los Estados miembros; es por ello por lo que el artículo 54 del Protocolo de Trujillo prevé que los países miembros coordinarán sus planes de desarrollo en sectores específicos y armonizarán gradualmente sus políticas económicas y sociales con la mira de llegar al desarrollo integrado del área, mediante acciones planificadas.

La referenciada articulación supone, adicionalmente, la articulación de las competencias andinas y las competencias de las entidades territoriales descentralizadas. En el marco de cualquier proceso de integración supranacional, resulta de relevancia armonizar los distintos intereses y competencias de las entidades territoriales (o sus homólogos) con los intereses nacionales y supranacionales (Rodríguez, 2014). Por ello es por lo que generalmente, en los procesos de integración más avanzados, las competencias que se ejercen en los distintos niveles no son excluyentes; por el contrario, dichas competencias, deben ejercerse dentro de los principios de coordinación, concurrencia y subsidiariedad (Marcelli, 2008). Al respecto, el Estado ha apartado de sus intereses las relevantes y significativas actividades que en el marco internacional pueden ofrecer las entidades territoriales. Es por ello necesario refrendar el amplio significado del desarrollo de actividades internacionales por parte de las entidades territoriales (Blanco y Gómez, 2016).

Otro presupuesto de orden político que permite que el proceso andino de integración funcione es la legalización del establecimiento de un presupuesto comunitario. La CAN no podrá abordar con seriedad ni profundidad sus responsabilidades sin unas instituciones con la debida capacidad económica. Esto impone la necesidad de constituir un presupuesto comunitario que permita cumplir con la gestión propia de la CAN. Este deberá estar equilibrado en cuanto a ingresos y gastos, y todos los ingresos y gastos de la can habrán 
de estar incluidos en las oportunas provisiones que se elaboren con anterioridad a cada ejercicio presupuestario ${ }^{11}$ (Cortés, 2013).

\section{Conclusiones}

En aras de que la CAN pueda funcionar políticamente en el contexto de los Estados miembros, es necesaria la voluntad política de los Estados que conforman la CAN para promover y fortalecer el proceso andino de integración y, como consecuencia de ello, la voluntad política de cesión del ejercicio de soberanía por parte del Estado colombiano a la CAN. De otro lado, es importante consolidar la legitimidad del proceso andino de integración, la coordinación de la institucionalidad que conforma a la CAN, la autonomía en el ejercicio de las funciones de los órganos comunitarios, la articulación entre el plan de desarrollo del Estado colombiano y las políticas del proceso andino de integración, la

11 En la actualidad, el presupuesto de la can depende de los traslados presupuestales que los gobiernos miembros realizan directamente al presupuesto de dicho órgano internacional. Esa obligación de los Estados miembros se materializa a través del pago de la cuota comunitaria, sin que dicha actividad se gestione a través de un presupuesto comunitario. Dicho sistema de cuotas ha hecho evidente la vulnerabilidad presupuestal y financiera de la CAN en razón de que los recursos con los que se ha mantenido su presupuesto representan un alto nivel de riesgo porque dependen de la aprobación presupuestal de los gobiernos nacionales. Lo anterior ha dado lugar a demoras en la asignación de los recursos y afectan directamente el flujo de caja y, en términos generales, la seguridad financiera y de funcionamiento de la can. Consideramos que los países andinos son los únicos responsables del precario financiamiento de los órganos de la CAN, al incumplir de forma reiterada y flagrante sus obligaciones de contribuir al presupuesto de sus respectivos órganos e instituciones. De hecho, los Estados miembros han dejado al Tribunal de Justicia Andino en graves dificultades económicas, y este se ha visto incluso obligado a tener que endeudarse a través de la solicitud de créditos a la Comunidad Andina de Fomento (CAF), debido a que los Estados miembros no pagaron o se retrasaron en el pago de sus cuotas durante años. Ahora bien, la Secretaria General también ha venido sufriendo problemas presupuestarios que han sido denunciados en múltiples ocasiones (Del Solar, 1992). De la experiencia puede extraerse con facilidad la conclusión de que los Estados miembros de la CAN, con unas economías internas ampliamente deterioradas, han descuidado voluntariamente la financiación del sistema institucional andino, ocasionando graves problemas de funcionamiento. Como puede también suponerse, los Estados tampoco se han esmerado en buscar fórmulas para revertir esta situación y para evitar problemas futuros. Consideramos que seguramente la solución más efectiva a corto plazo consistiría en que los Estados andinos asumieran y cumplieran el compromiso de incluir en sus presupuestos generales una partida específica destinada a financiar la integración andina. 
tipificación de que el proceso andino de integración se constituya como una política de Estado y el establecimiento de un presupuesto comunitario.

Para que la CAN produzcan la finalidad por la cual fue creada, es necesario que opere en el marco de Estados democráticos en los que se garantice la trivisión del poder. En este orden de ideas, si bien en el Estado colombiano existen las ramas judicial, ejecutiva y legislativa, es preciso no olvidar que la CAN también evidencia esa misma característica, ya que en su estructura orgánica existen órganos encargados de adelantar competencias judiciales (Tribunal Andino de Justicia), competencias ejecutivas (Consejo Andino de Presidentes y Consejo Andino de Ministros de Relaciones Exteriores) y competencias legislativas (Consejo Andino de Ministros de Relaciones Exteriores y, en algún modo, el Parlamento Andino). De otro lado, es pertinente recordar que, si bien Colombia es un Estado democrático, el ingreso de cualquier Estado a la CAN supone su tipificación como tal, aspecto corroborado por el Protocolo de Democracia, suscrito por todos los países miembros de la comunidad.

Es importante que los gobiernos nacionales andinos lideraren el proceso andino de integración como un sistema que supera la simple cooperación internacional. En este sentido, atendiendo a que en la actualidad el concepto clásico de soberanía está siendo objeto de fuertes cuestionamientos, dichos gobiernos deben comprender y asumir el compromiso del proceso andino de integración asimilándolo a un proceso de cooperación de soberanías con los demás Estados miembros y, como consecuencia de ello, fortalecer el concepto de soberanía supranacional. Hay que configurar, además, el proceso andino de integración como política de Estado, lo que supone por parte de este la promoción de una cultura política de integración y de la autonomía de las competencias de la CAN. 


\section{REFERENCIAS}

Ayala, E. (2007). Enseñanza de integración en los paises andinos. Quito: Corporación Editora Nacional.

Barragán, D. (2016). La construcción de la mentalidad democrática como necesidad en el posconflicto. Via Inveniendi et Iudicandi, 11(1), 37-57.

Barros, C. (1989). Atribuciones del Parlamento Andino como órgano principal del Acuerdo de Cartagena y orientador del proceso de integración subregional. Revista Integración Latinoamericana, (146-147), 34-67.

Bayón Mohino, J. C. (2007). Ciudadanía, soberanía y democracia en el proceso de integración europea. Anuario de Filosofía del Derecho, (XXIV). Recuperado de http://vlex.com/ $\mathrm{vid} / 42886186$

Blanco, C. (2013a). Algunas propuestas frente a la crisis de legitimidad de la comunidad andina. Revista Análisis Politico, 26(78), 56-89.

Blanco, C. (2013b). Aproximación a la noción de soberanía estatal en el marco del proceso andino de integración. Revista Republicana, (15), 34-67.

Blanco, C. (2013c). La Comunidad Andina en el marco de lo jurídico y político. Prolegómenos - Derechos y Valores, 26(31), 78-90.

Blanco, C. (2014). La crisis de la Comunidad Andina. Revista de Derecho, (42), 45-78.

Blanco, C. (2015a). La conexión entre descentralización territorial colombiana e integración andina. Análisis Político, 28(85), 78-98.

Blanco, C. (2015b). La influencia positiva de la CAN en la descentralización territorial colombiana. Revista Opinión Jurídica, 14(27), 56-67.

Blanco, C. y Gómez, D. (2016). Constitución política e integración andina desde las nociones de soberanía y democracia. En N. E. Pardo Posada (Ed.), Perspectivas críticas del derecho constitucional colombiano (pp. 107-127). Bogotá: Universidad Libre. https://doi.org/ https://doi.org/10.18041/978-958-5466-14-2

Cortés, S. (2013). La globalización económica y los derechos humanos. Via Inveniendi et Iudicandi, 8(2), 56-78. 
De Donini, A. (2014). El sector educativo del Mercosur en el marco de la integración regional: una mirada evaluativa al Plan de Acción 2006-2010. Recuperado de http://vlex. com/vid/69549120

Del Solar, A. (1992). La institucionalidad en el Grupo Andino. (No. Documento LC/R. 1151 (10 de junio)). Santiago de Chile.

Forero Salcedo, J. R. (2014). El valor superior de la justicia en la Unión Europea. Especial referencia al Estado constitucional social y democrático de derecho español. Revista Verba Iuris, (31), 91-114. Recuperado de https://revistas.unilibre.edu.co/index.php/ verbaiuris/article/view/59/53

Gallego, J. (2014). Paradoja y complejidad de los derechos humanos en la sociedad moderna: sentido y comunicación. IUSTA, (40), 143-165.

Garzón, E. (2013). Globalización del derecho, fetichismo legal el velo de los derechos humanos. Verba Iuris, (30), 45-78.

Guarín, E. A. y Aldana, J. (2016). Estado jurisdiccional y bien común. Verba Iuris, 11(36), $13-26$.

Herrera, W. (2001). De la organización territorial (título XI de la Constitución Política). Revista de Derecho de la División de Ciencias Jurídicas, (15). Recuperado de http://vlex. $\mathrm{com} / \mathrm{vid} / 51671171$

Humbarita, J. (2015). Derecho constitucional Hispanoamericano frente a la realidad institucional, manifiesta divergencia. IUSTA, 43(2), 45-78.

Jablkowski, L. (2008). Participación y ciudadanía: implicaciones psicológicas en los procesos de participación. En P. Ibarra e I. Ahedo (Eds.), Democracia participativa y desarrollo humano (pp. 57-75). Dykinson. Recuperado de http://vlex.com/vid/41013413

Liwski, N. (2006). Situación de la Argentina en el escenario mundial. Congreso de Adolescencia y Juventud 2006. En la N. y los A. (IIN) Instituto Interamericano del Niño (Ed.), Simposio Construcción de Ciudadanía en la adolescencia y vigencia de los derechos.

Magilevich, A. (1972). La comunidad supranacional. Santiago de Chile: Convenio Andrés Bello.

Marcelli, F. (2008). Actividades internacionales de las regiones italianas. Criterio Jurídico, 8(2). Recuperado de http://vlex.com/vid/51760789 
Maside Miranda, J. E. (1992). Características del derecho comunitario europeo. Revista Critica de Derecho Inmobiliario, (610), 1147-1180. Recuperado de http://vlex.com/ $\mathrm{vid} / 327206$

Molina del Pozo, C. F. (2005). Una constitución para Europa: nuevo paso en el proceso de integración. En C. F. Molina del Pozo, A. Faiña Medín y J. B. Mata Diz (Eds.), El diálogo entre los pueblos y culturas en el marco de las relaciones latinoamericanas. Dijusa. Recuperado de http://vlex.com/vid/44666420

Morata, F. (1987). La ejecución del derecho comunitario en los estados miembros descentralizados: un enfoque jurídico-político. Revista Catalana de Derecho Público, (7). Recuperado de http://vlex.com/vid/67881784

Ortiz Jiménez, W. (2007). Cultura política y ciudadanía: estudio para los municipios que conforman el área metropolitana del valle de Aburrá. Ratio Juris, (5), 143-151.

Palomares, J. y Calonje, N. (2015). Tratados de libre comercio Colombia-Asia: cuestión preliminar y perfiles de negociación. IUSTA, 43(1), 17-41.

Patarroyo, S. y Benavides, P. (2014). Rupturas asignificantes: revisiones críticas en torno al derecho. Via Inveniendi et Iudicandi, 9(1), 7-31.

Pérez Luño, A.-E. (2002). Ciudadanía y definiciones. Doxa. Cuadernos de Filosofía del Derecho, (25), 177-211. https://doi.org/https://doi.org/10.14198/DOXA2002.25.05

Quindimil, J. (2006). Instituciones y derecho de la Comunidad Andina. Valencia: Tirant lo Blanch.

Quiroz, M. (2014). Acercamiento a las “oposiciones paradigmáticas” entre neoconstitucionalismo y positivismo jurídico. IUSTA, 41(2), 77-97.

Ramírez, G. (2006). Avances y retos de la educación en derechos humanos en el siglo xxi: De América Latina a México. En J. C. Gutiérrez Contreras (Ed.), Educación en derechos humanos (pp. 179-206). Ciudad de México: Universidad Nacional Autónoma de México (Unam). Recuperado de http://ru.juridicas.unam.mx/xmlui/bitstream/handle/123456789/11379/avances-y-retos-de-la-educacion-en-derechos-humanos-en-elsiglo-xxi-de-america-latina-a-mexico.pdf?sequence $=12 \&$ isAllowed $=y$

Rodríguez, A. (2014). Indicadores de constitucionalidad de las políticas públicas: enfoque de gestión de derechos. Via Inveniendi et Iudicandi, 9(2), 135-175. 
Ruano, B. (2006). Globalisation de la forme scolaire. En G. Chapelle y D. Meuret (Eds.), Améliorer l'école. París: PUF.

Tirado, M., Bedoya, J. y Blanco, A. (2016). Bioética y transhumanidad: hacia una aproximación al consumo de sustancias nootrópicas en el campo académico. En D. Carreño Dueñas, Y. M. Guerra, J. A. Restrepo Restrepo, J. Becerra, M. Tirado Acero, J. C. Bedoya Chavarriaga, ... M. Martínez Cruz (Eds.), Bioética y Docencia. Bogotá: Universidad Santo Tomás - Grupo Editorial Ibáñez. Recuperado de https://repository.usta.edu.co/ handle/11634/1527 